\title{
9. STUDIES IN DETOXICATION
}

\section{THE SYNTHESIS OF SOME POSSIBLE BIOLOGICAL OXIDATION PRODUCTS OF SULPHANILAMIDE}

\author{
By W. V. THORPE AND R. TECWYN WILLIAMS \\ From the Physiology Department, Medical School, Hospitals Centre, Birmingham
}

(Received 19 December 1940)

In the previous paper [Thorpe \& Williams, 1941] we expressed the opinion that 1-amino-2-hydroxy-(II) and l-amino-3-hydroxy-benzene-4-sulphonamide (V) and 2-oxybenzoxazole-6-sulphonamide (I) might be biological oxidation products of sulphanilamide. Here we describe the synthesis of these compounds. No difficulty was experienced in the preparation of the $o$-aminophenol and benzoxazole derivatives which were obtained at different stages in the same synthesis, but the synthesis of the $m$-aminophenol derivative presented unexpected difficulties:
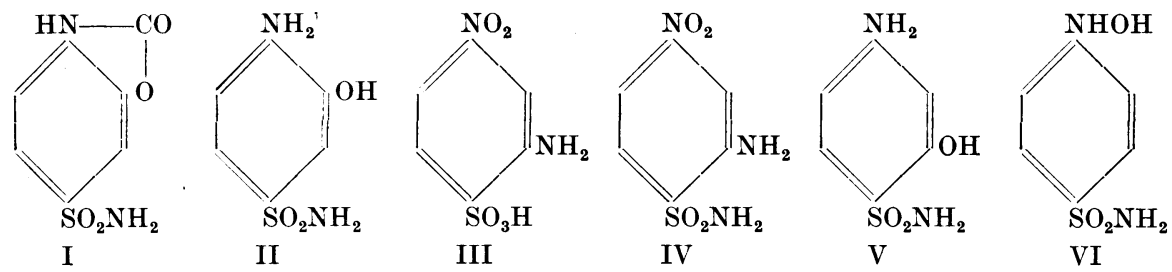

We first attempted a synthesis of 1-amino-3-hydroxybenzene-4-sulphonamide $(\mathrm{V})$, starting with the easily prepared $m$-nitraniline-sulphonic acid (III). It was hoped to obtain large amounts of 1-nitro-3-aminobenzene-4-sulphonamide (IV), and thence, by diazotization and reduction, the required $m$-aminophenolsulphonamide. We found, however, after many trials using different chlorinating agents, that the nitranilinesulphonic acid formed little or none of the corresponding sulphonyl chloride. Small amounts of (IV) were eventually obtained in one experiment using chlorosulphonic acid, but this result could not be repeated. This proposed method of synthesis was therefore abandoned. One interesting point which emerged at this stage was that ammonium 1-nitro-3-aminobenzene4-sulphonate was isolated in a dimorphous state, a pale orange and a red form. The orange form could be easily converted into the red form by gentle warming below $100^{\circ}$. The red form, once formed, was apparently stable.

Success was eventually attained starting with $m$-aminophenolsulphonic acid, which is easily prepared by heating $m$-aminophenol with conc. $\mathrm{H}_{2} \mathrm{SO}_{4}$. The synthesis worked smoothly to the sulphonyl chloride stage, whilst the final stages were completed with some difficulty.

Although many workers (see previous paper for literature) state that they have used $p$-hydroxylaminobenzenesulphonamide (VI) in biological work, no mention is made in their papers of its method of preparation or chemical properties. This substance has been prepared by Bratton et al. [1939] and we have repeated their process and agree with their description of its chemical properties. 
We have also prepared its $N$-acetyl derivative ${ }^{1}$ which has M.P. $227^{\circ}$ and gives no diazo reaction in agreement with Bratton et al. [1939]. We mention this since James [1940] claims to have isolated this acetyl compound from human urine after sulphanilamide medication, and states that the substance he isolated did not melt below $300^{\circ}$. We failed to prepare $p$-hydroxylaminobenzenesulphonamide using Bamberger's [1894] method with zinc dust at low temperatures, and Haworth \& Lapworth's [1921] sodium hydrosulphide method for the preparation of arylhydroxylamines.

The phenolic sulphonamides (II) and (V) have not yet been tested for therapeutic activity. Of phenolic sulphonamides which have been tested for therapeutic activity, 1-hydroxy-2-aminobenzene-4-sulphonamide [Tréfouel et al. 1937; McLeod, 1938] and $p$-hydroxybenzenesulphonamide [Buttle et al. 1936; McLeod, 1938] were inactive, and 1-hydroxy-3-nitrobenzene-4-sulphonamide [McLeod, 1938] was active. Compounds related to our 1-nitro-3-aminobenzene4-sulphonamide have also been tested and found inactive, namely 1-nitro; 4-aminobenzene-3-sulphonic acid [Buttle et al. 1936] and 1-nitro-6-aminobenzene-3-sulphonamide [Tréfouel et al. 1937].

\section{EXPERIMENTAL}

2-Oxybenzoxazole-6-sulphonyl chloride. Benzoxazolone (2-oxybenzoxazole) was prepared from salicylamide and $\mathrm{NaOCl}$ according to Graebe \& Rostovzeff [1902]. The only modification introduced was that the benzoxazolone was precipitated from the alkaline reaction mixture by neutralizing carefully, with cooling, with conc. $\mathrm{HCl}$ instead of by passing $\mathrm{CO}_{2}$ into the solution: The neutralization with $\mathrm{CO}_{2}$ may take several hours (on a $20 \mathrm{~g}$. scale) whilst with $\mathrm{HCl}$ it can be done in under half an hour. Sodium benzoxazolonesulphonate was prepared according to the patent directions [Friedländer, 1911]. The dry salt $(10 \mathrm{~g}$.) was stirred with $12 \mathrm{~g}$. $\mathrm{PCl}_{5}$. The mass warmed up and became pasty, and after standing half an hour with occasional stirring, it was treated with ice water in the usual manner. The precipitated chloride was filtered, washed with water and dried (yield 6 g.). It crystallized from toluene in colourless rhombic plates, M.P. 186-187.$^{2}$ (Found: $\mathrm{C}, 36 \cdot 2 ; \mathrm{H}, 1 \cdot 8 ; \mathrm{N}, 6 \cdot 1 \%$. $\mathrm{C}_{7} \mathrm{H}_{4} \mathrm{O}_{4} \mathrm{NClS}$ requires $\mathrm{C}, 36.0$; $\mathrm{H}, 1 \cdot 7 ; \mathrm{N}, 6 \cdot 0 \%$ ).

2-Oxybenzoxazole-6-sulphonamide (I) was prepared by adding the powdered chloride to strong ammonia. The deposit formed overnight was filtered and dissolved in warm dilute $\mathrm{NaOH}$. On cooling, the sodium salt of the sulphonamide separated as needles, which were recrystallized from water. (Found: $\mathrm{N}, 10 \cdot 2 ; \mathrm{Na}$, $8 \cdot 4 ; \mathrm{H}_{2} \mathrm{O}, 13 \cdot 4 \%$. $\mathrm{C}_{7} \mathrm{H}_{5} \mathrm{O}_{4} \mathrm{~N}_{2} \mathrm{SNa}, 2 \mathrm{H}_{2} \mathrm{O}$ requires $\mathrm{N}, 10 \cdot 3 ; \mathrm{Na}, 8 \cdot 45 ; \mathrm{H}_{2} \mathrm{O}, 13 \cdot 2 \%$.) The sulphonamide itself immediately separates as needles if an aqueous solution of the sodium salt is acidified. On recrystallization from water, the sulphonamide formed needles, M.P. $263^{\circ}$. (Found: C, 39.4; $\mathrm{H}, 2 \cdot 8 ; \mathrm{N}, 13 \cdot 3 \%$. $\mathrm{C}_{7} \mathrm{H}_{6} \mathrm{O}_{4} \mathrm{~N}_{2} \mathrm{~S}$ requires $\mathrm{C}, 39 \cdot 25 ; \mathrm{H}, 2 \cdot 8 ; \mathrm{N}, 13 \cdot 1 \%$.)

1-Amino-2-hydroxybenzene-4-sulphonamide (II). $2.8 \mathrm{~g}$. of the foregoing sodium salt were boiled for $20 \mathrm{~min}$. with $25 \mathrm{ml}$. of $30 \% \mathrm{NaOH}$. Crystals of

1 We experienced some difficulty in this acetylation. Using acetic anhydride as recommended by Bratton et al. we persistently obtained a product melting about $160^{\circ}$ from which Bratton's acetyl derivative was only obtained in small yield by fractional crystallization. We did not examine the other product in detail except to note that it gave a diazo reaction, and prove that it was not unchanged $p$-hydroxylaminobenzenesulphonamide. It may be the substance responsible for Rosenthal and Bauer's diazo reaction (see Thorpe \& Williams [1941]).

2 All melting-points are uncorrected. 


\section{ERRATA}

\section{Volume 35, Nos. $1 \& 2$}

p. 62, line 13 of text

for 1-hydroxy-3-nitrobenzene-4-sulphonamide

read 1-hydroxy-2-nitrobenzene-4-sulphonamide 
$\mathrm{Na}_{2} \mathrm{CO}_{3}$ separated in the solution, and were liable to cause violent bumping. The solution was cooled, carefully neutralized, with conc. $\mathrm{HCl}$ and then made alkaline with solid $\mathrm{Na}_{2} \mathrm{CO}_{3}$. The solution was now extracted for $8 \mathrm{hr}$. with ether in a continuous extractor and on evaporation of the ether the sulphonamide was obtained as a crystalline residue $(2 \mathrm{~g}$.). The compound was pürified by dissolving in hot absolute alcohol and adding sufficient carbon tetrachloride to produce a faint cloudiness; on cooling the sulphonamide separated as clusters of long needles, M.P. $164^{\circ}$. It was soluble in water and alcohol, sparingly soluble in ether and insoluble in $\mathrm{CCl}_{4}$. It reduced ammoniacal silver nitrate on warming and gave a purple colour with $\mathrm{FeCl}_{3}$ turning a deep red in about 30 sec. It slowly caused the formation of methaemoglobin in a $\mathrm{l}$ ' in 50 solution of blood at $37^{\circ}$. (Found: $\mathrm{C}, 38 \cdot 6 ; \mathrm{H}, 4 \cdot 3 ; \mathrm{N}, 15 \cdot 6 \% . \mathrm{C}_{6} \mathrm{H}_{8} \mathrm{O}_{3} \mathrm{~N}_{2} \mathrm{~S}$ required $\mathrm{C}, 38 \cdot 3 ; \mathrm{H}, 4 \cdot 3 ; \mathrm{N}, 14 \cdot 9 \%$.) The hydrochloride was prepared by adding the requisite amount of conc. $\mathrm{HCl}$ to an alcoholic solution of the sulphonamide. On stirring the solution the hydrochloride separated; more alcohol was now added and the solution boiled until the hydrochloride dissolved. Carbon tetrachloride was then poured into the solution until the hydrochloride just began to crystallize and the crystallization was completed at $0^{\circ}$. It formed fine matted needles, which were very soluble in water and which decomposed without melting above $300^{\circ}$. It was purified by crystallization from absolute alcohol and $\mathrm{CCl}_{4}$. (Found: $\mathrm{C}, 32.3 ; \mathrm{H}, 3.9 ; \mathrm{N}$, $12 \cdot 6 \%$. $\mathrm{C}_{6} \mathrm{H}_{8} \mathrm{O}_{3} \mathrm{~N}_{2} \mathrm{~S} . \mathrm{HCl}$ requires $\mathrm{C}, 32 \cdot 1 ; \mathrm{H}, 4 \cdot 0 ; \mathrm{N}, 12 \cdot 5 \%$.)

Treatment of an aqueous solution of the sulphonamide with benzoyl chloride and $\mathrm{NaOH}$ gave 1-benzamino-2-benzoxybenzene-4-sulphonamide, which formed needles from aqueous alcohol, .M.P. 191 ${ }^{\circ}$. (Found: C, 60.0; H, 3.9; N, 7.4\%. $\mathrm{C}_{20} \mathrm{H}_{16} \mathrm{O}_{5} \mathrm{~N}_{2} \mathrm{~S}$ requires $\mathrm{C}, 60 \cdot 6 ; \mathrm{H}, 4 \cdot 1 ; \mathrm{N}, 7 \cdot 1 \%$.)

1-Amino-3-hydroxybenzene-4-sulphonic acid was prepared by sulphonation of $m$-aminophenol [cf. Friedländer, 1896]. $15 \mathrm{~g}$. of $m$-aminophenol were heated on the water bath with $25 \mathrm{ml}$. conc. $\mathrm{H}_{2} \mathrm{SO}_{4}$ and a few drops of fuming $\mathrm{H}_{2} \mathrm{SO}_{4}$ for an hour. The solid product was broken up in about $150 \mathrm{ml}$. of water and $10 \%$ $\mathrm{NaOH}$ added with stirring until a clear solution was obtained. The solution was row filtered, acidified with $\mathrm{HCl}$ and set aside to crystallize at $0^{\circ}$. The acid (tablets) was filtered, washed with water and dried over $\mathrm{CaCl}_{2}$; yield $24 \mathrm{~g}$.

Pyridine 1-acetamino-3-acetoxybenzene-4-sulphonate. The above acid (10g.) was shaken with $25 \mathrm{ml}$. pyridine and then $25 \mathrm{ml}$. acetic anhydride added. Addition of the anhydride caused the evolution of heat; the solution was therefore cooled under the tap. The acid dissolved in about an hour, the solution being occasionally shaken to facilitate solution. The mixture solidified on keeping at room temperature overnight. The solid was filtered under suction, pressed and washed with small amounts of methylated spirit. It was recrystallized from spirit, ether being added to facilitate the crystallization. On evaporating the mother liquor from the acetylation mixture in vacuo, a small amount of the salt was recovered; yield $15 \mathrm{~g}$. M.P. $170-172^{\circ}$. The substance gave no colour with $\mathrm{FeCl}_{3}$ and no diazo reaction. (Found: $\mathrm{N}, 7 \cdot 9 \% \cdot \mathrm{C}_{15} \mathrm{H}_{16} \mathrm{O}_{6} \mathrm{~N}_{2} \mathrm{~S}$ requires $\mathrm{N}, 7 \cdot 95 \%$.)

1-Acetamino-3-acetoxybenzene-4-sulphonyl chloride. The foregoing pyridine salt (5 g.) was stirred with $5 \mathrm{~g}$. $\mathbf{P C l}_{5}$. The mixture soon became pasty and warm. After 15-20 min., the mixture was heated for a few minutes on the water bath. The product was then thrown into ice-water and, on stirring, the chloride separated as a white solid (yield almost quantitative). It crystallized from toluene as long rods, M.P. $169^{\circ}$. (Found: $\mathrm{C}, 41 \cdot 4 ; \mathrm{H}, 3 \cdot 4 ; \mathrm{N}, 4.85 \% \cdot \mathrm{C}_{10} \mathrm{H}_{10} \mathrm{O}_{5} \mathrm{NClS}$ requires C, $41 \cdot 2 ; \mathrm{H}, 3 \cdot 45 ; \mathrm{N}, 4 \cdot 8 \%$.)

1-Acetamino-3-hydroxybenzene-4-sulphonamide. The above chloride was added to 5 times its weight of $40 \%$ ammonia $\left(40 \mathrm{ml}\right.$. $\mathrm{NH}_{4} \mathrm{OH}$ sp.gr. 0.880 made 
up to $100 \mathrm{ml}$. with water). The chloride gradually dissolved, the solution becoming warm. After an hour the opalescent solution was filtered and evaporated to a thin paste on the water bath. After cooling, the paste was stirred with about 5 vol. water and the sparingly soluble crystalline material collected and washed with water. The 1-acetamino-3-hydroxybenzene-4-sulphonamide was recrystallized from $50 \%$ aqueous alcohol as colourless needles, M.P. $280^{\circ}$ decomp. (The meltingpoint was observed after raising the temperature fairly rapidly up to about $270^{\circ}$; if heated very slowly decomposition sets in about $250^{\circ}$, observed meltingpoint may be as low as $265^{\circ}$ and it is difficult to get consistent results.) Yield of crude product $30 \%$. weight of chloride. The pure substance gave no diazo reaction. A violet colour with $\mathrm{FeCl}_{3}$ was obtained with a solution of the amide in $50 \%$ aqueous alcohol. (Found: $\mathrm{C}, 41.8 \% ; \mathrm{H}, 4.5 ; \mathrm{N}, 12.2 \% . \mathrm{C}_{8} \mathrm{H}_{10} \mathrm{O}_{4} \mathrm{~N}_{2} \mathrm{~S}$ requires $\mathrm{C}, 41 \cdot 75 ; \mathrm{H}, 4 \cdot 4 ; \mathrm{N}, 12 \cdot 2 \%$.)

The mother liquor from the separation of this amide gave on further evaporation crystalline material (yield up to $10 \%$ weight of chloride) rather more soluble than the main product. It crystallized from $30 \%$ aqueous alcohol in apparently homogeneous needles, M.P. $235^{\circ}$. It gave no diazo reaction, but readily gave a violet colour with $\mathrm{FeCl}_{3}$ with an aqueous solution. On hydrolysis with $2 \mathrm{~N}$ $\mathrm{NaOH}$, it yielded 1-amino-3-hydroxybenzene-4-sulphonamide. $\mathrm{C}, \mathrm{H}$ and $\mathrm{N}$ values $(\mathrm{C}, 42.6 ; \mathrm{H}, 4.5 ; \mathrm{N}, 11 \cdot 1 \%$ ) gave no clue to the nature of this substance (mixture?) and we did not investigate it further.

The filtrate from the separation of the. unidentified substance appeared to contain small amounts of this unidentified substance or the above amide (or both) and also some acetylated 1-amino-3-hydroxybenzene-4-sulphonic acid, since after hydrolysis with $2 \mathrm{~N} \mathrm{NaOH}$ some 1-amino-3:hydroxybenzene-4sulphonamide could be obtained by extraction with ether, and 1-amino-3hydroxybenzene-4-sulphonic acid (yield up to $10 \%$ weight chloride) separated in tablets on acidifying with $\mathrm{HCl}$.

1-Amino-3-hydroxybenzene-4-sulphonamide (V). 1-Acetamino-3-hydroxybenzene-4-sulphonamide ( $1 \mathrm{~g}$.) was dissolved in $10 \mathrm{ml} .2 \mathrm{~N} \mathrm{NaOH}$ and heated in a boiling water bath for $3 \frac{1}{2} \mathrm{hr}$. Water lost by evaporation was replaced at intervals. (Hydrolysis with $2 N \mathrm{HCl}$ was equally effective.) The mixture was then made neutral or just acid by addition of conc. $\mathrm{HCl}$ and finally rendered just alkaline by addition of solid $\mathrm{Na}_{2} \mathrm{CO}_{3}$. The solution was extracted with ether in a continuous extractor for at least $8 \mathrm{hr}$. 1-Amino-3-hydroxybenzene-4-sulphonamide separated from the extract in clusters of long colourless plates (yield $0.5 \mathrm{~g}$.). A further crop $(0.1 \mathrm{~g}$.) was obtained by evaporation of the ether, but the product obtained in this way was liable to turn brown on keeping unless it was immediately purified. The amide was recrystallized by taking up in a small amount of absolute alcohol followed by addition of $\mathrm{CCl}_{4}$ until cloudy. The amide gradually crystallized in long plates which had M.P. $152^{\circ}$ and gave a strong diazo reaction and a weak redviolet colour with $\mathrm{FeCl}_{3}$. It was readily soluble in water and alcohol, sparingly soluble in ether, insoluble in $\mathrm{CCl}_{4}$. (Found: $\mathrm{C}, 38 \cdot 7 ; \mathrm{H}, 4 \cdot 4 ; \mathrm{N}, 14 \cdot 6 \% \cdot \mathrm{C}_{6} \mathrm{H}_{8} \mathrm{O}_{3} \mathrm{~N}_{2} \mathrm{~S}$ requires $\mathrm{C}, 38.3 ; \mathrm{H}, 4 \cdot 3 ; \mathrm{N}, 14.9 \%$.) On adding conc. $\mathrm{HCl}$ to a concentrated aqueous solution, the hydrochloride separated in elongated rhombic plates which could be recrystallized from a small volume of $80 \%$ aqueous alcohol. By shaking an aqueous solution of the amide with acetic anhydride, the monoacetyl derivative M.P. $280^{\circ}$ already described separated from the solution. The amide did not cause formation of methaemoglobin when incubated with a 1 in 50 blood solution.

1-Nitro-3-aminobenzene-4-sulphonamide (IV). m-Nitraniline was sulphonated according to Friedländer [1923] and 1-nitro-3-aminobenzene-4-sulphonic acid isolated as the sparingly soluble sodium salt. Treatment of the dry $\mathrm{Na}$ salt or of 
the free acid itself with $\mathrm{PCl}_{5}$, thionyl chloride or chlorosulphonic acid failed to give any indication of the formation of the sulphonyl chloride except in one case. An account of this isolated case is given, but we must emphasize that this experiment could not be repeated. $20 \mathrm{~g}$. of the dry $m$-nitranilinesulphonic acid were heated on the water bath for $3.5 \mathrm{hr}$. with $20 \mathrm{ml}$. of chlorosulphonic acid. The resulting thick liquid was poured into ice-water with stirring. A yellow precipitate separated which was filtered and washed twice with water. After pressing as dry as possible, it was stirred into $200 \mathrm{ml}$. ammonia (sp. gr. 0.880), in which it immediately dissolved. After $24 \mathrm{hr}$. at room temperature a deposit (6 g.) of clear light brown prisms of large size separated, having M.P. 213-214 ${ }^{\circ}$. On evaporating the mother liquor ammonium 1-nitro-3-aminobenzene-4-sulphonate was obtained. This salt crystallized at room temperature as large orange prisms, but if the temperature of crystallization was above room temperature, then a mixture of bright red and orange crystals was obtained. The orange form could be easily converted into the red form on heating in a test tube at about $80^{\circ}$. The red form once formed appeared to be stable: (Found, orange form: $\mathrm{C}, 30 \cdot 8 ; \mathrm{H}, 3 \cdot 8 ; \mathrm{N}, 17 \cdot 6 \%$ : red form, C, 30.5; $\mathrm{H}, 3 \cdot 8 ; \mathrm{N}, 17 \cdot 8 \% \cdot \mathrm{C}_{6} \mathrm{H}_{9} \mathrm{O}_{5} \mathrm{~N}_{3} \mathrm{~S}$ requires $\mathrm{C}, 30.6 ; \mathrm{H}, 3.9 ; \mathrm{N}, 17.9 \%$.) The light brown crystals of M.P. $213-214^{\circ}$ appeared to be mainly 1-nitro-3-aminobenzene-4-sulphonamide, contaminated with some of the above ammonium salt. The crystals were recrystallized from water and formed yellow prismatic needles, M.P. $215^{\circ}$. (Found: C, 33.3; H, $3 \cdot 2 \%$. $\mathrm{C}_{6} \mathrm{H}_{7} \mathrm{O}_{4} \mathrm{~N}_{3} \mathrm{~S}$ requires $\mathrm{C}, 33 \cdot 2 ; \mathrm{H}, 3 \cdot 25 \%$.)

\section{SUMMARY}

The synthesis of 1-amino-2-hydroxybenzene-4-sulphonamide, 2-oxybenzoxazole-6-sulphonamide, 1-amino-3-hydroxybenzene-4-sulphonamide and several related compounds is described. Their preparation was necessitated beoause they may be biological oxidation products of sulphanilamide.

1-Amino-2-hydroxybenzene-4-sulphonamide is a methaemoglobin-former in vitro, but 1-amino-3-hydroxybenzene-4-sulphonamide is not.

We wish to express our gratitude to Prof. W. N. Haworth and Dr M. Stacey, who arranged for the $\mathrm{C}, \mathrm{H}$ and some of the $\mathrm{N}$ estimations to be done by their micro-analyst.

\section{REFERENCES}

Bamberger (1894). Ber. dtsch. chem. Ges. 27, 1548.

Bratton, White \& Marshall (1939). Proc. Soc. exp. Biol., N.Y., 42, 847.

Buttle, Gray \& Stephenson (1936). Lancet, 1, 1289.

Friedländer (1896). Fortschr. Teerfarb. 3, 59 (D.R.P. 71,229).

- (1911). Fortschr. Teerfarb. 9, 148 (D.R.P. 197,496).

- (1923). Fortschr. Teerfarb. 13, 242 (D.R.P. 294,547).

Graebe \& Rostovzeff (1902). Ber. dtsch. chem. Ges. 35, 2751.

Haworth \& Lapworth (1921). J. chem. Soc. 119, 768.

James (1940). Biochem. J. 34, 640.

McLeod (1938). Biochem. J. 32, 1770.

Thorpe \& Williams (1941). Biochem. J. 35, 52.

Tréfouel, Tréfouel, Nitti \& Bovet (1937). Ann. Inst. Pasteur, 58, 39. 